\title{
Optimizing the geometry of the connecting rod in opposite pistons engine
}

\begin{abstract}
The article presents the results of simulations research carried out, using Finite Element Method. The simulations were made in the Abaqus software. Studies were related to the reduction and improving of stress distribution in the connecting rod of opposite pistons combustion engine. The connecting rod has been developed in a 3D environment in the Catia software, then imported into the simulation tool, in which stress tests were performed. The connecting rod was subjected to a compression and stretching tests. Boundary conditions of forces used in simulation tests have been developed on the basis of the dynamic model created in the MSC Adams software. The study included nine iterations of geometric changes of connecting rod. Shape as well as properties such as parametric dimensions (rod length) were changed. The changes were dictated by the reduction of the maximum values of the stresses and the size of the fields with large stress values. As a result of the simulations, the improvement of the connecting rod strength was obtained by its geometrical change (which was obtained by reducing the stress fields).
\end{abstract}

Key words: connecting rod, simulation, FEM, Abaqus, Catia v5

\section{Introduction}

In aircraft propulsions systems, the new trends are for searching the solutions to reduce operating costs and mass of engines, while maintaining reliability. In the case of ultralight aircrafts, the essential feature of the propulsion system is the type of fuel that engine will be supplied. Particularly important feature, is its affordability and price of the fuel. Currently, most of the piston engines used in aviation are powered by AVGAS100LL fuel, which is expensive and increasingly difficult to access. Fuels available for most airports are JET-A and automotive fuels, such as ES95 and diesel fuel [2].

Some of aircraft engines used in aviation can be powered by diesel fuel and JET-A fuel. The advantage of those fuels is also low flammability and lower price compared to AVGAS100LL fuel. In addition, the specific fuel consumption in diesel engines is lower than in spark-ignition engines, which reduces the mass of fuel required to be used for the same fly mission distance, allowing greater mass to be carried in, despite the increased mass of the propulsion unit. These are the main advantages for the use of this type of the propulsion systems.

In addition, after analyzing the use of ultralight engines in aviation, in case of their cylinder system, it turned out that the dominant configuration of the engine, was the flat boxer cylinder system and the system with opposed pistons. The engines of this type are lighter, because the aligned cylinders/pistons counterbalance the inertia forces and there is no need to use additional balancing masses improving the rotation speed uniformity $[8,9]$. Therefore, a system with opposing pistons was chosen based on the analysis for the engine design.

The designed connecting rod will be used in a Diesel engine. This engine will be characterized by opposing pistons positions. Ultimately, the propulsion unit will be used in the ultralight aircraft.

Because of the engine design, where the cylinders are located flat with pistons placed opposite, engine has to have two short crankshafts orientated against each other, which indirectly determines the connecting rod construction [3].
Because the engine is designed from the beginning, it is necessary to use advanced simulation tools to determine the dimensions and geometry of the main components of the crank-piston system.

\section{Simulation research}

The strength tests of the connecting rod were based on the Abaqus software, using the Finite Element Method. This method consists of solving differential equations based on the division of the domain (so-called discretization) into finite elements for which the solution is approximated by specific functions, and performing real calculations only for the nodes of that division [5]. This software allows to calculate the reduced strengths values for all compute nodes according to the mesh grid. To perform full strength calculations of a given element, it is needed to go through several steps necessary to build the correct model:

a) import of engine parts solid models,

b) modernization of solid models,

c) adding material properties,

d) arrangement of solid models,

e) interaction and correlation between elements,

f) adding restraints and forces acting on elements,

g) constructing a mesh grid,

h) computing process,

i) visualization and analysis of results.

At each stage, it is necessary to maintain the appropriate quality of research, so that reliable simulation results can be obtained. In order to optimize the connecting rod's shape, it has undergone several stages of strength calculations, any change in the design or geometry of the connecting rod resulted in the need to repeat all of the above mentioned steps.

In the first stage of the work, only the initial strength analysis was performed to verify the accuracy of the geometry and the selection of the appropriate mesh grid. The initial part of the article presents an introduction to simulation research involving the construction of a mesh grid and its verification in the form of a maximum load resulting from the force acting on the main engine components from 
the combustion process. After the mesh grid was verified, the target model was constructed, based on the preliminary results [1].

\subsection{Initial model}

In the preliminary stage of the study, the model consist of the upper connecting rod part, cap, rod bushing, rod bearing inserts. All of the listed parts are shown in Fig. 1 and were previously imported into the Abaqus software.

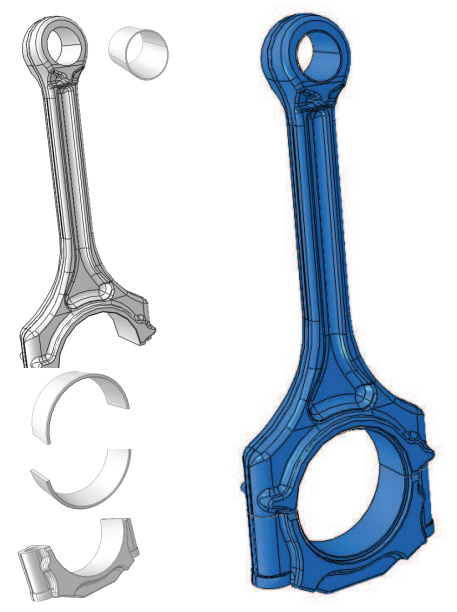

Fig. 1. Elements and assembly of the connecting rod

Due to the assembly of the connecting rod from several components it was necessary to give the contact properties on the contact surfaces between each elements. Contact properties were defined and assigned between such elements as:

a) upper part of connecting rod - cap,

b) upper part of connecting rod - rod bushing,

c) upper part of connecting rod - upper rod bearing insert,

d) cap - bottom rod bearing insert.

Figure 2 shows all contacts occurring in the model with reference to the above list.
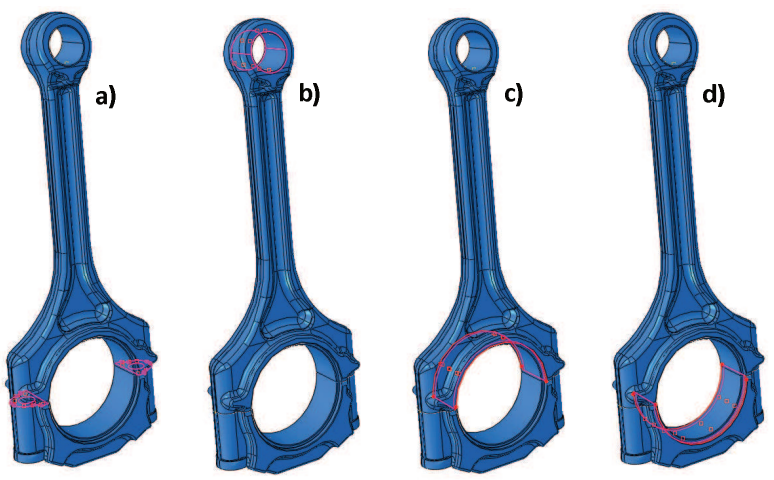

Fig. 2. Contact surfaces between individual elements

Due to the type of the connecting rod work process, it was decided to calculate its strength at the time of occurrence of the maximum force resulting from the combustion pressure. As conditions of restraint and conditions of forces acting on the connecting rod, it was decided to introduce the following:

a) fixation of the inner part of rod bearing inserts, b) fixing the side surface of upper and lower part of the connecting rod,

c) fixing of the upper side surface of the connecting rod upper part,

d) fixing of the side surface of rod bushing,

e) force acting on the inner bottom side of the rod bushing. All boundary conditions are presented in Fig. 3 with reference to the above list.
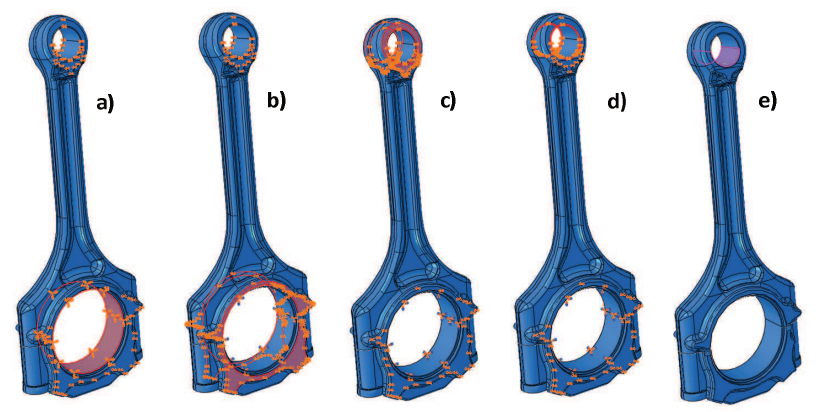

Fig. 3. Boundary conditions of restraints and forces acting on the model

As the material properties of the individual parts, it was decided to choose 40HNMA steel for the upper and lower connecting rods parts and Ti-3Al-8V-6Cr-4Mo-4Zr Beta C (TM) for all bushings [6, 4, 10]. The materials properties used in simulations are presented in Tables 1 and 2.

Table 1. 40HNMA steel material properties used for calculations

\begin{tabular}{|l|c|}
\hline Material properties & Value \\
\hline Poisson number & 0.3 \\
\hline Density & $7850 \mathrm{~kg} / \mathrm{m}^{3}$ \\
\hline Young module & $207 \mathrm{GPa}$ \\
\hline
\end{tabular}

Table 2. Ti-3Al-8V-6Cr-4Mo-4Zr Beta C (TM) material properties used for calculations

\begin{tabular}{|l|c|}
\hline Material properties & Value \\
\hline Poisson number & 0.341 \\
\hline Density & $8860 \mathrm{~kg} / \mathrm{m}^{3}$ \\
\hline Young module & $110 \mathrm{GPa}$ \\
\hline
\end{tabular}

In order to select the appropriate mesh grid, it was decided to conduct the optimization process of the grid in subsequent calculation steps. The initial size of the grid element was $4 \mathrm{~mm}$ and the final $1.1 \mathrm{~mm}$ (as shown in Fig. 4). Table 3 shows the size of the components and their number for all parts of the connecting rod.

For each of the cases, the generation of the mesh grid was performed and initial strength calculations were made to determine the accuracy of the mesh.

\begin{tabular}{|c|c|c|c|c|c|}
\multicolumn{7}{|c|}{ Table 3. Size and number of elements } \\
\cline { 2 - 6 } & \multicolumn{5}{|c|}{ Elements number } \\
$\begin{array}{c}\text { Element } \\
\text { size }\end{array}$ & $\begin{array}{c}\text { Upper } \\
\text { part }\end{array}$ & Cap & $\begin{array}{c}\text { Rod } \\
\text { bushing }\end{array}$ & $\begin{array}{c}\text { Upper } \\
\text { rod } \\
\text { bearing } \\
\text { instert }\end{array}$ & $\begin{array}{c}\text { Bottom } \\
\text { rod } \\
\text { bearing } \\
\text { instert }\end{array}$ \\
\hline $4 \mathrm{~mm}$ & 19535 & 8260 & 415 & 702 & 702 \\
\hline $3 \mathrm{~mm}$ & 27356 & 12221 & 683 & 1216 & 1216 \\
\hline $2 \mathrm{~mm}$ & 47686 & 23602 & 1488 & 2547 & 2547 \\
\hline $1.5 \mathrm{~mm}$ & 81415 & 43133 & 2782 & 5992 & 5992 \\
\hline $1.2 \mathrm{~mm}$ & 180374 & 92551 & 4763 & 11042 & 11042 \\
\hline $1.1 \mathrm{~mm}$ & 180374 & 92551 & 4763 & 11042 & 11042 \\
\hline
\end{tabular}


Because some part of the connecting rod (bush and bearings inserts) are characterized by a small thickness, for the correctness of the calculation, the local density compaction of the mesh grid was decided in the next step. It is assumed that at least 3 mesh elements must be at the thickness of the thin-walled body, in order to avoid erroneous results, it was decided to use 5 elements. This operation was performed for all bushes and bearing inserts. Figure 5 shows the mesh grid view, generated for these parts using the local mesh compaction process.
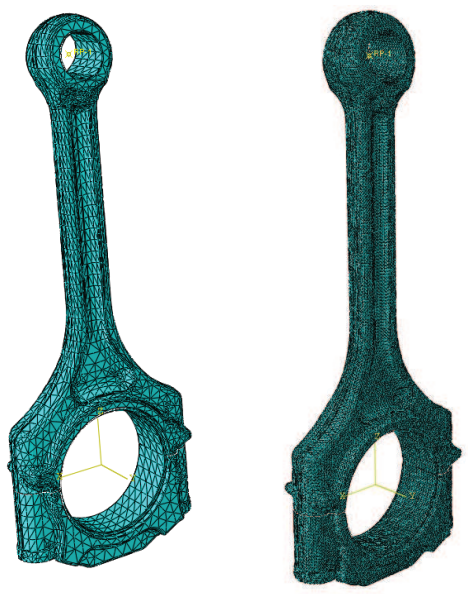

Fig. 4. Mesh grid view for $4 \mathrm{~mm}$ and $1.1 \mathrm{~mm}$ size of elements
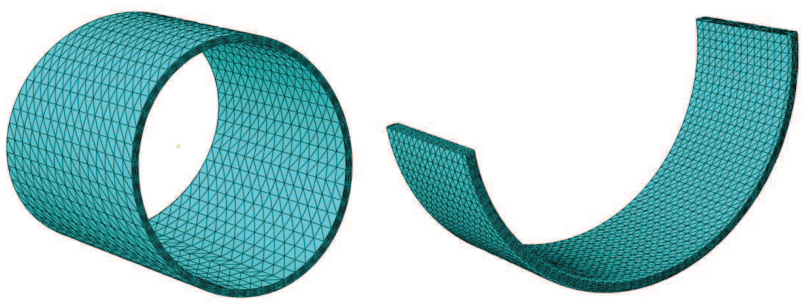

Fig. 5. Mesh grid with local density on bushing and bearing insertions

The rest of the elements have not been changed, and for the rod bushing, the new grid elements number was 10767 and for the upper and bottom rod bearing inserts was 17530. The prepared model has been subjected to the same calculation process. The main result of the presented initial simulation calculations is to determine the accuracy of the mesh grid. As it is clear from the preliminary calculations, the size of the element at $1.2-1.1 \mathrm{~mm}$ along with the local mesh density in the thin-walled components allows for reliable results. This means that the size of the grid element does not negatively affect the results of the simulation tests. The same model was used in the publication [7].

\subsection{Main models}

This section contains the results of the connecting rod strength calculations together with the history of changes in its geometry to reduce zones, where there is a dangerous stress area. Calculations were made in Abaqus software, and geometry changes after each calculation cycle were performed in Catia v5 software. In total, 8 connecting rod models and one target model were presented.

In order to reduce the time to optimize its geometric shape, it was decided to calculate the connecting rod only for compression. This mainly helped to change the shape of the constriction of the connecting rod I-beam. Boundary conditions and material properties are identical to those previously accepted for initial strength calculations. The same is the visualization of the computational grid selected for the models below. During the work on changing the geometry of the connecting rod, length of the rod has changed. In each case, the conditions of the loading force acting on the connecting rod were redefined and introduced into the calculation model.

To clearly presents the geometry changes of the connecting rod, it was decided to firstly present the results of the strength simulation of all 8 connecting rod models. After each model, geometric changes were included in the next release and all geometry models are presented together with the history of changes in their geometry, as well as final verification calculations for the target model at the end of the paper.

In order to shorten the calculation time in all models, it was decided to apply the restriction condition at the point of contact with the crankshaft and to give the compressive force acting along the connecting rod to the lower surface of the rod bushing. For a clear presentation of data, it was decided to set the same visualization parameters, i.e. the maximum stress was set at $300 \mathrm{MPa}$ and the minimum at $0 \mathrm{MPa}$. This review, make it possible to compare the simulation results of the various models between each other.

\section{Connecting rod - model 1}

The model 1 contained a very small cross-sectional area of the I-beam and did not take into account the geometric requirements for the size of the rod bushing or rod bearing inserts. As we can see, the stresses in this model significantly exceeded $300 \mathrm{MPa}$, which was due to the too small cross-sectional area of the I-beam.
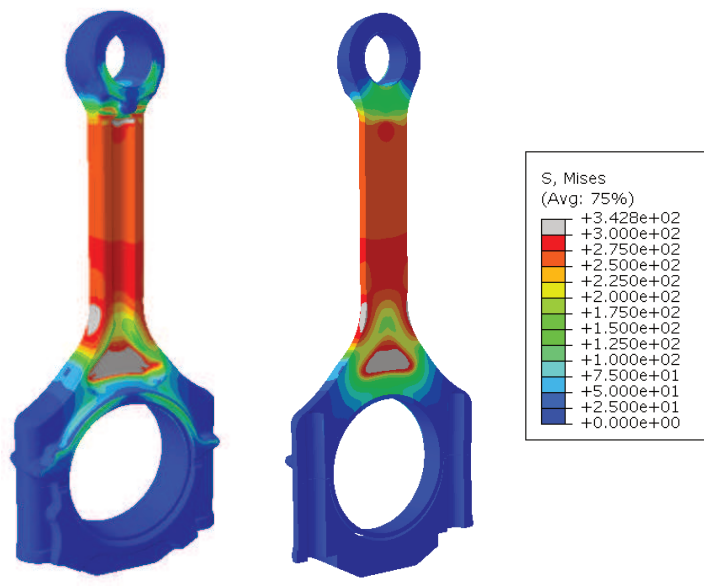

Fig. 6. Results of simulation of connecting rod model 1

Connecting rod - model 2

Model 2 has been significantly changed in comparison to model 1. The cross-sectional area of the I-beam was enlarged. The shape of the rod small and big end were completely changed. The geometrical changes were shown in Fig. 7. As shown in the figures, the stress level is significantly reduced but there are still local spots in the upper and lower parts of the connecting rod, where the stresses exceed $300 \mathrm{MPa}$. 


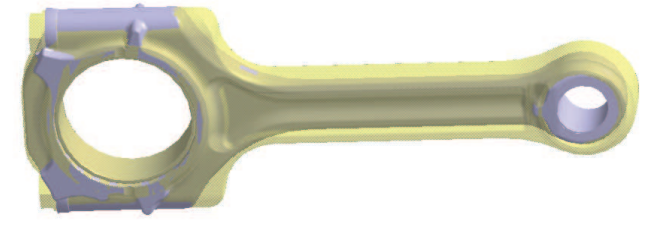

Fig. 7. Geometric changes between model 1 (gray) and model 2 (yellow)
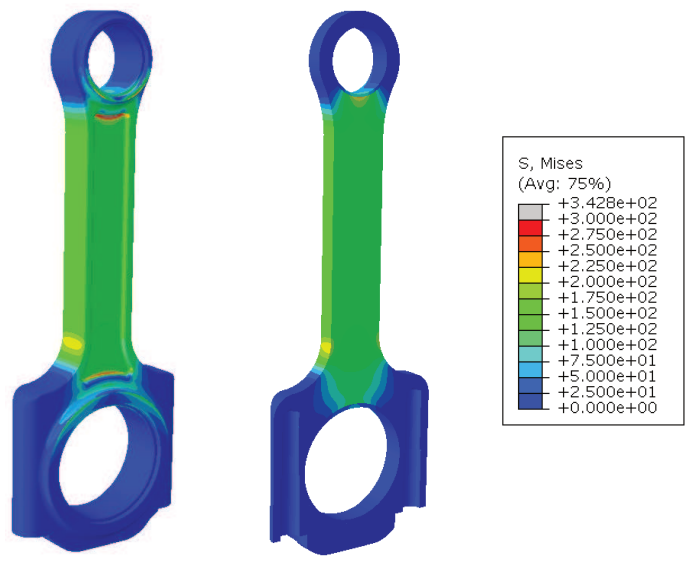

Fig. 8. Results of simulation of connecting rod model 12

\section{Connecting rod - model 3}

Model 3 has been changed in comparison to model 2 by changing the geometry of the rod small end and changing the geometry of the I-beam (mass reduction). The geometry changes are shown in Fig. 9. As shown in the figures, due to the mass reduction in the I-beam, the stress value is higher. By contrast, increasing the dimensions of the rod small end resulted in a more uniform distribution of stresses in this part.

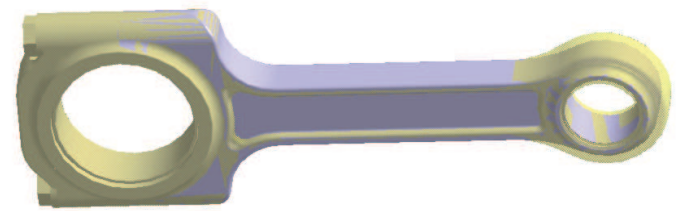

Fig. 9. Geometric changes between model 2 (gray) and model 3 (yellow)
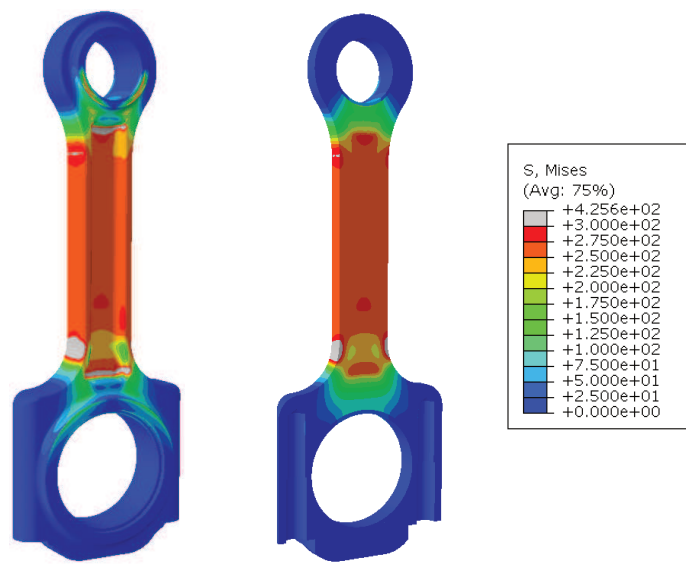

Fig. 10. Results of simulation of connecting rod model 3

\section{Connecting rod - model 4}

Model 4 has been changed in comparison to the model 3 by changing the geometry of I-beam and changing the outer curves describing the transition between I-beam and cap. The geometrical changes are shown in Fig. 11. As can be seen in the figures, changes in the shape of the outer lines between the I-beam and rod small end and cap, resulted in a change in the stress distribution.

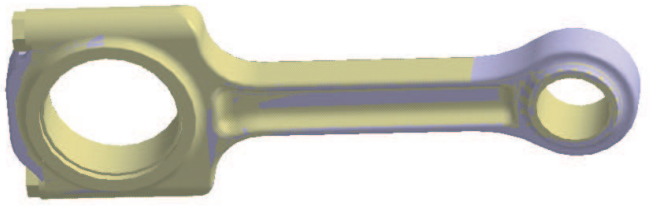

Fig. 11. Geometric changes between model 3 (gray) and model 4 (yellow)

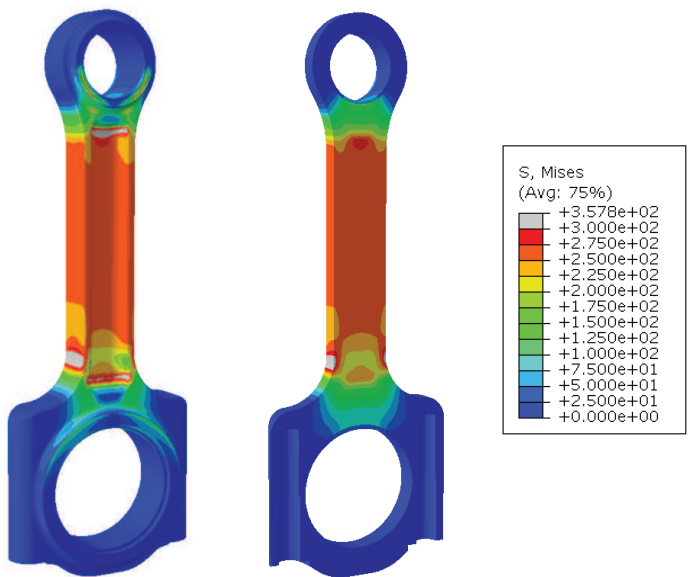

Fig. 12. Results of simulation of connecting rod model 4

\section{Connecting rod - model 5}

Model 5 has been significantly changed in comparison to model 4 in the geometry of I-beam, cap and small end. It was decided to accept a different width of the rod small end and different shape of the cap. The geometric changes are shown in Fig. 13. As can be seen in the figures presented below, the geometric changes introduced in model allow for significant reduction of stresses in the entire connecting rod geometry.

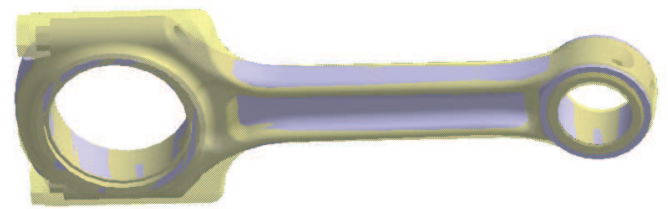

Fig. 13. Geometric changes between model 4 (yellow) and model 5 (grey)
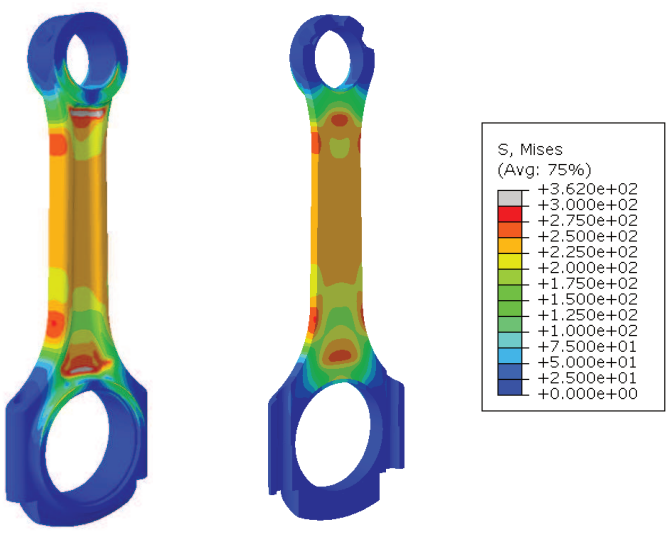

Fig. 14. Results of simulation of connecting rod model 5 


\section{Connecting rod - model 6}

Model 6 has been changed in comparison to model 5 by changing the connecting rod length (from 145 to $125 \mathrm{~mm}$ ). This change resulted from the changed of engine design assumptions. The geometry changes are shown in Fig. 15. As shown in the figures, the changes in the length of the connecting rod caused changes in the stress distribution in the connecting rod and the presence of high stresses on the outsides surfaces of the connecting rod.

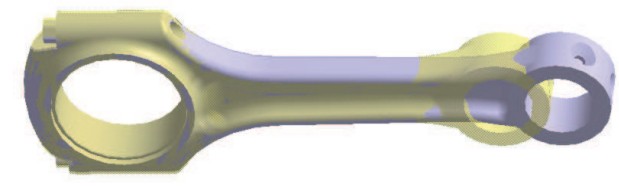

Fig. 15. Geometric changes between model 5 (gray) and model 6 (yellow)
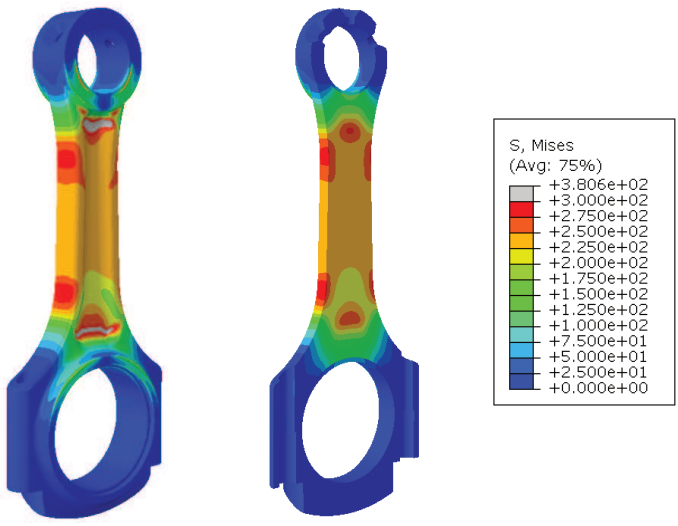

Fig. 16. Results of simulation of connecting rod model 6

\section{Connecting rod - model 7}

Model 7 has been slightly changed in comparison to model 6 by changing the geometry of the connecting rod Ibeam. The presented geometric changes are shown in Fig. 17. As can be seen in the figures, the changes in the geometry of the connecting rod have reduced the field of occurrence of the value of the maximum stresses on the outside surfaces of the connecting rod.

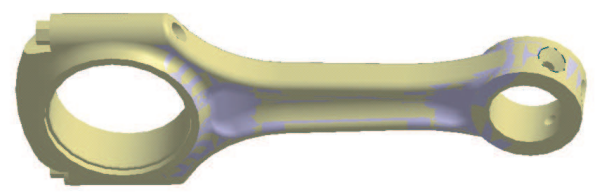

Fig. 17. Geometric changes between model 6 (yellow) and model 7 (gray)
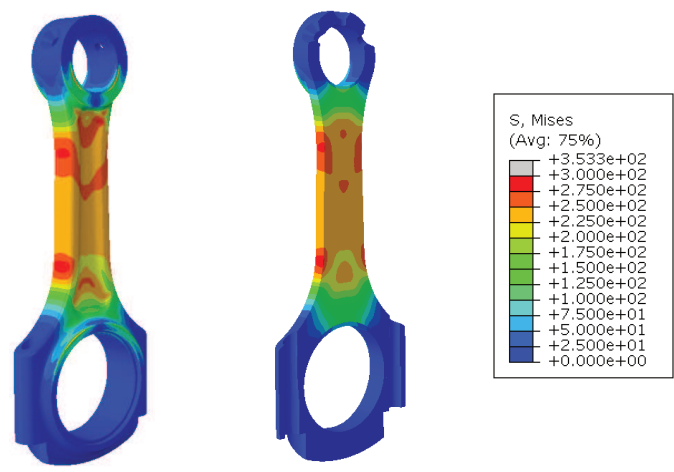

Fig. 18. Results of simulation of connecting rod model 7

\section{Connecting rod - model 8}

Model 8 has been changed in comparison to model 7 by changing the geometry of the I-beam and changing the connecting rod length (from $125 \mathrm{~mm}$ to $130 \mathrm{~mm}$ ). This change resulted from the changed engine design assumptions. The geometrical changes are shown in Fig. 19. As shown in the figures, the changes made to the connecting rod have changed the distribution of the stresses that have accumulated in the outside surfaces of the I-beam.

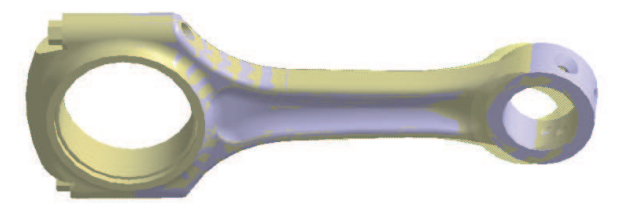

Fig. 19. Geometric changes between model 7 (yellow) and model 8 (grey)
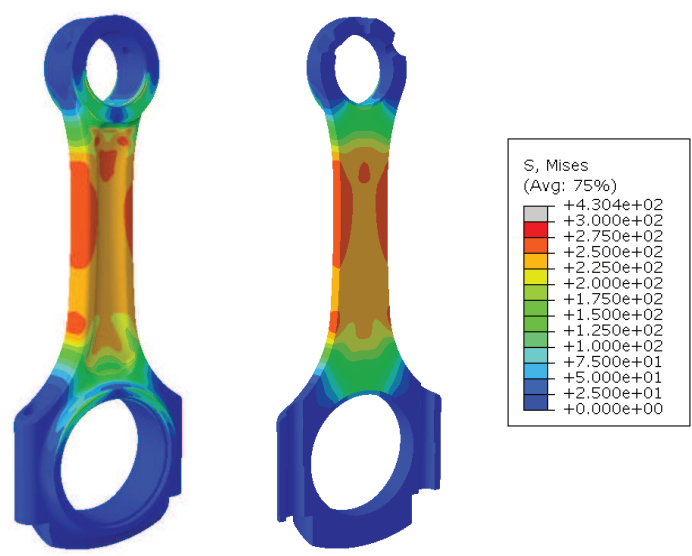

Fig. 20. Results of simulation of connecting rod model 8

Below, all intermediate versions of the connecting rod are shown as solid models.
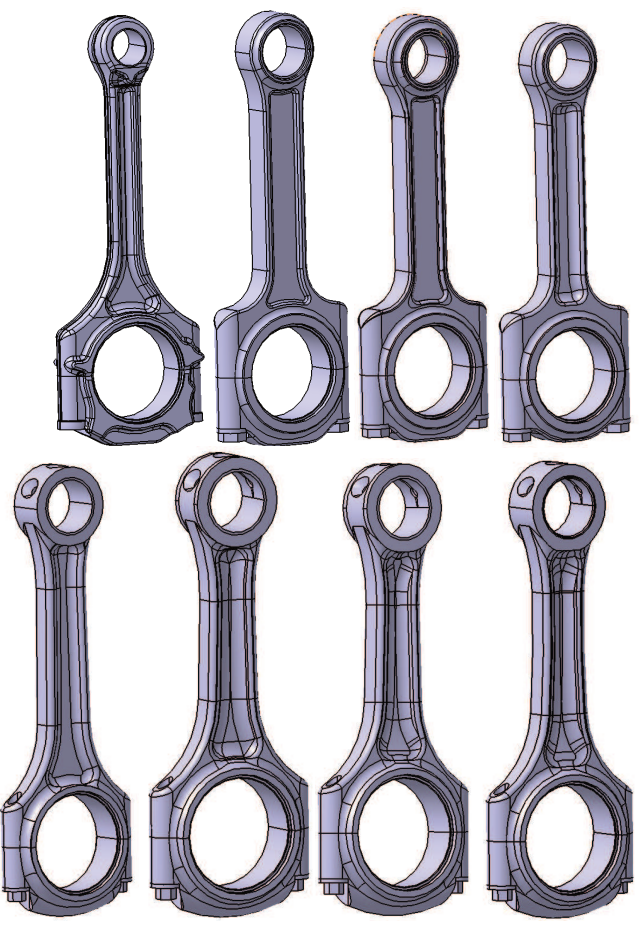

Fig. 21. All intermediate connecting rod models 


\section{Summary}

As a result of the simulations, the geometry of the connecting rod has changed. Part of the change, in particular the change in the length of the connecting rod was dictated by the design process of the entire crank-piston system, on which the authors of the article had no influence on. Changing the length of the connecting rod between successive modes significantly influenced the stress distribution. As can be seen from the results of the simulations, the level of stress, was significantly reduced. This was due, to the change in cross section of the connecting rod I-beam, but also to the introduced of geometric changes (change of the outer lines). During the design process, the fields with the maximum stress values on both sides of the connecting rod were reduced. All of the presented results had the same range of stresses as presented in figures, which makes possible to compare the results presented in the article between each other. The publication does not show results for the connecting rod extension. Those studies were carried out in the next research step and did not show any dangerous area of stress.

The results of the research show that using modern numerical methods helps to shorten the design process. In addition, it allows to reduce the mass of the tested element by changing its geometry. Compared to analytical methods (where only the cross section of the connecting rod I-beam can be calculated to the compression condition), computer methods allow for the visualization of the stress distribution and the determination of dangerous locations in the geometry of the examined element.

\section{Acknowledgement}

This work has been realized in the cooperation with The Construction Office of WSK "PZL-KALISZ" S.A. and is part of Grant Agreement No. POIR.01.02.00-00-0002/15 financed by the Polish National Centre for Research and Development.

\section{Nomenclature}

FEM finite element method

\section{Bibliography}

[1] ABDUL-LATEEF, W. Finite element analysis of connecting rod using Nastran software. The Iraqi Journal For Mechanical and Material Engineering. 2012, 12(2).

[2] FAROKHI, S. Aircraft propulsion, SBN: 978-1-118-806777, 2004.

[3] HEYWOOD, J.B. Internal combustion engine fundamentals. McGraw-Hill, USA, 1988.

[4] cartech.ides.com/datasheet.aspx?i=101\&E=270 korbowód

[5] pl.wikipedia.org/wiki/Metoda_element $\% \mathrm{C} 3 \% \mathrm{~B} 3 \mathrm{w}_{-}$ sko\%C5\%84czonych

[6] JOSHI, P., UMAIRZAKI, M., FEM analysis of connecting rod of different materials using ANSYS. International Journal of Engineering and Techniques. 2015, 3(1).

Paweł Magryta, MEng. - Faculty of Mechanical Engineering at the Lublin University of Technology.

e-mail:P.Magryta@pollub.pl

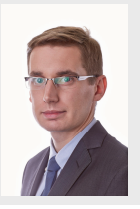

Adam Majczak, MEng. - Faculty of Mechanical Engineering at the Lublin University of Technology. e-mail:A.Majczak@pollub.pl
[7] MAGRYTA, P., PIETRYKOWSKI, K. The influence of load distribution in kinematic constraints of connecting rod on the results of the stress simulation. Combustion Engines. 2017.

[8] PIRAULT, J., FLINT, M. Opposed piston engines evolution, use and future applications. SAE International. ISBN 978-0-7680-1800-4.

[9] REGNER, G., JOHNSON, D., KOSZEWNIK, J., DION, E. et al. Modernizing the opposed piston, two stroke engine for clean, efficient transportation. SAE Technical Paper. 2013, 2013-26-0114.

[10] WELSCH, G., BOYER, R., COLlINGS, E.W. Materials properties handbook: titanium alloys. Metals Park, Ohio: ASM International, 1994.

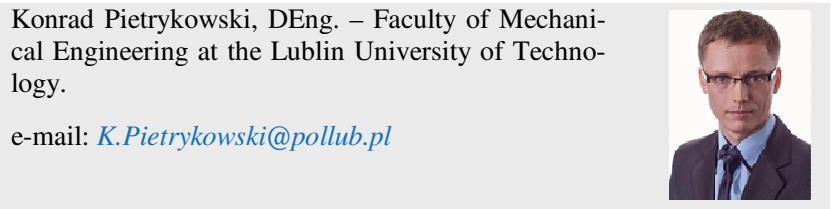

